\title{
Meeting Chairs Appointed to Steer 1986 Spring Meeting
}

\author{
Chu, Quinn, and Thompson Plan Comprehensive High-Tech Program
}

The MRS Program Committee has announced that the 1986 MRS Spring Meeting in Palo Alto, California will be headed by three dynamic MRS members, Wei-Kan Chu, Rod K. Quinn, and Malcolm J. Thompson.

Dr. Chu, professor in the Department of Physics and Astronomy at the University of North Carolina at Chapel Hill, is a founder and current president of the North Carolina Section of MRS. He has also served as a co-chair of the 1980 MRS symposium, Semiconductor Interfaces, and the 1983 symposium, Thin Films and Interfaces. A frequent speaker at MRS meetings, he also serves on the Society's Publications Committee.

Dr. Quinn is a division supervisor, Inorganic Materials Chemistry Division, at Sandia National Laboratories, Albuquerque, New Mexico. His current research centers around surface chemistry of oxides, e. g., lithium metal reaction with silica and silicates studied by AES and RBS, and solution preparation of glasses and ceramics. Quinn has presented a number of papers at MRS
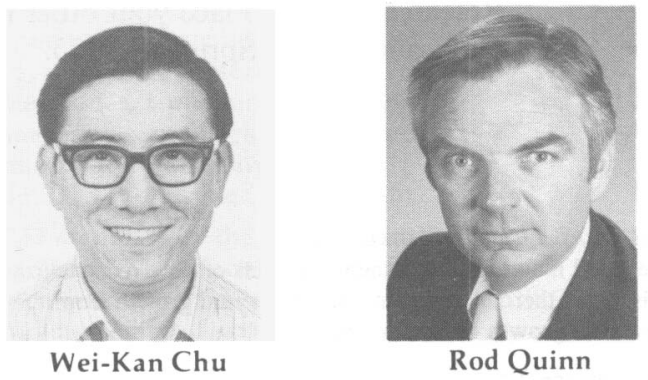

Rod Quinn

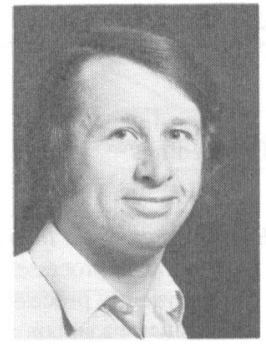

Malcolm Thompson symposia and most recently served as chairman in charge of local arrangements for the 1984 MRS Spring Meeting, held in Albuquerque.

Dr. Thompson, area manager in the Integrated Circuit Laboratory at Xerox Palo Alto Research Center, investigates aspects of thin film devices, metal semiconductor interfaces, amorphous silicon, and defects in silicon when not participating in Society activities. He has presented a number of papers at MRS meetings and co-chaired the symposium, Comparison of Thin Film Transistor and SOI Technology, at the 1984 Spring Meeting. He is currently co-chairman of the symposium, Materials Aspects of Amorphous Silicon Technology, to be held at the upcoming Spring Meeting in San Francisco.

"We are very excited about the West Coast 1986 Spring Meeting," Chu said. "The concentration of high-technology industry, the high-quality research at many institutes nearby, and the comparable ease of access for people across the Pacific, combine to provide the perfect environment for this MRS meeting.

"We have planned the symposia around several key areas requiring interdisciplinary efforts for ureak-throughs. We are delighted to work with many enthusiastic chairs to plan and coordinate the symposia at this rapidly growing annual event."

\section{MRS Corporate Affiliates}

The Society recognizes the interest and support of the following corporate affiliates.

AG Associates

Air Products and Chemicals

ALCOA

Allied Corporation

Applied Materials

ARCO Metals Company

ARCO Solar, Inc.

AT\&T Bell Laboratories

AT\&T Technologies, Inc.

Branson, IPC

Brimrose Corporation of America

Brush Wellman, Inc

Cameca Instruments, Inc

CEMCOM Research Associates

CILAS Alcatel

Combustion Engineering, Inc.-

Power Systems

Denton Vacuum, Inc.

Drytek, Inc.

E. I. du Pont de Nemours \&

Company

Dynavac

Eastman Kodak Company

Eaton Corporation
ELKEM Chemicals, Inc.

Elsevier North-Holland

Energy Conversion Devices, Inc.

Charles Evans \& Associates

Exxon Research and

Engineering Company

Ferranti, pic

GCA Corporation

General Electric Ceramics, Inc

General Electric Company

General lonex Corporation

General Motors Research

Laboratories

GTE Laboratories

Harshaw/Filtrol

Helionetics

Hirst Research Centre

Hitachi Scientific Instruments

Imperial Chemical Industries, plc

Instruments SA, Inc

International Business

Machines Corporation

JEOL USA

Lam Research
Lambda Physik

Lanxide Corporation

Lasertechnics

Lawrence Livermore National Laboratory

LFE Corporation

Los Alamos National Laboratory

Lumonics

3M Company

Martin Marietta Laboratories

Materials Research Corporation

Microscience, Inc.

Monsanto

National Electrostatics

Corporation

Newport Corporation

Perkin-Elmer

Philips Electronic Instruments, Inc.

Plasma-Therm Systems, Inc.

Portland Cement Association

Quantronix Corporation

Questek, Inc.

Sandia National Laboratories

Schlumberger-Doll Research
SOHIO Chemicals \& Industrial Products Company

Solar Energy Research Institute

Solarex

Spectra Physics

Spire Corporation

Standard Oil of Indiana

Stauffer Chemical Company

Surface Science Laboratories, Inc.

Tegal Corporation

TRW

Union Carbide Corporation

United Technologies Research Center

UOP

Varian/Extrion

VG Instruments, Inc.

W. R. Grace \& Company

Westinghouse Electric

Corporation

Xerox Corporation

$X M R$

Zymet 


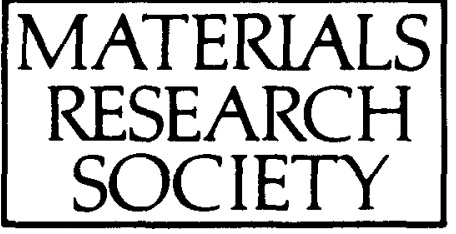

\section{PROCEEDINGS 1984 MRS FALL MEETING}

Be sure to order your copies of the proceedings of this landmark meeting of the Materials Research Society. Place your order now and receive priority shipment of the volumes upon publication in the Spring of 1985.

Proceedings

A Energy Beam-Solid Interactions and Transient Thermal Processing

(ultrafast processes in highly excited materials, fundamental aspects of bulk recrystallization, transiently processed materials, rapid thermal annealing, silicon crystal growth from the melt over insulators, silicon solid phase crystal growth on insulators)

C Impurity Diffusion and Gettering in Semiconductors (impurity behavior, impurity diffusion, oxygen in silicon)

D Layered Structures, Epitaxy and Interfaces (quantum well structures, epitaxy of thin films, insulators on silicon, strained-layer superlattices, metastable structures, epitaxial metals on semiconductors, interfaces )

F Plasma Synthesis and Etching of Electronic Materials (plasma etching mechanisms; plasma deposition of thin films, plasma oxidation, nitridation and passivation of surfaces; silane plasmas and thin film deposition; plasma etching and microfabrication plasma processes and diagnostics, recent developments in plasma etching, deposition and diagnostics

G High-Temperature Ordered Intermetallic Alloys (theory of order and phase stability, microstructural features and phase transformation, mechanical behavior, alloy design and microstructural control, physical and metallurgical properties)

J Electronic Packaging Materials Science

(overview, processing materials and structures, electronic packaging materials science, mechanical properties, metal and polymer interfaces, characterization of surfaces and interfaces, adhesion and metal ceramic interfaces)

K Advanced Photon and Particle Techniques for the Characterization of Defects in Solids (point defects and clusters, extended defects and defect arrays, surface defects and adsorbates, grain boundaries, defects in implanted materials, interface and thin film structures)

L Potential for Very High Strength Cement-Based Materials

(microstructure and fracture, pore structure and its effect on properties, properties and mix design for structural applications, novel non-structural applications)

M Coal Combustion and Conversion Wastes: Characterization, Utilization and Disposal (characterization, leaching and disposal, utilization)

N Scientific Basis for Nuclear Waste Management VII (leaching mechanisms, materials performance in repository environments, radiation effects, modeling, near field interactions and related investigations, research at DOE Materials Characterization Center, geochemical interactions and natural analogues, materials science of concrete in waste management, processing technology)

Extended Abstracts (available for immediate shipment)

B Laser Chemical Pracessing of Semiconductor Devices

(144 pages - laser-assisted growth of semiconductor films, process diagnostics, metallization from thin films and gases, fundamental processes, photochemical etching, dielectric photoformation)

I Graphite Intercalation Compounds (272 pages - synthesis and intercalation mechanisms, electronic structure, magnetic properties, photons, structure and phase transitions, graphite fibers, novel materials)

o Alloy Phase Diagrams

(108 pages - surfaces and defects, calculations: data handling)

P Fractal Aspects of Materials: Metal and Catalyst Surfaces, Powders and Aggregates (54 pages)
Member Price

$\$ 36$

$\$ 36$

$\$ 30$

$\$ 25$

Prepayment is required on all book orders (includes postage and handling). Send orders to Publications Department, Materials Research Society, 9800 McKnight Road, Suite 327 , Pittsburgh, PA 15237, telephone (412) 367-3003. 